\title{
Phenomenal Consciousness: A Critical Analysis of Knowledge Argument, Inverted Spectrum Argument and Conceivability Argument
}

\section{Manas Kumar Sahu*}

Research Scholar, Humanities and Social Sciences Department, Indian Institute of Technology Bombay Powai, Mumbai, Maharashtra-400076, India

DOI: $10.36348 /$ jaep.2020.v04i04.004

| Received: 04.04.2020 | Accepted: 11.04.2020 | Published: 18.04.2020

*Corresponding author: Manas Kumar Sahu https://orcid.org/0000-0001-7537-6828

Email: manassahu23@gmail.com,manas.hss@ iitb.ac.in

\section{Abstract}

The objective of this paper is to defend the non-reductive thesis of phenomenal consciousness. This paper will give an overview of the arguments for the non-reductive explanation of phenomenal consciousness and justify why the reductionist approach is implausible in the context of explaining phenomenal subjective experience. The debate between reductionist and non-reductionist on the project of Demystifying and Mystifying phenomenal consciousness is driven by two fundamental assumptions-1) Reductive-Naturalistic Objectivism, 2) Phenomenal Realism. There are several arguments for the irreducibility of phenomenal consciousness; this paper will focus on the inverted spectrum argument, knowledge argument, and the conceivability argument.

Keywords: Phenomenological Consciousness, Knowledge Argument, Conceivability Argument, Invertspecturm Argument, Ability Hypothesis, Acquaintance Hypothesis.

Copyright @ 2020: This is an open-access article distributed under the terms of the Creative Commons Attribution license which permits unrestricted use, distribution, and reproduction in any medium for non-commercial use (NonCommercial, or CC-BY-NC) provided the original author and sources are credited.

\section{INTRODUCTION}

Consciousness is the most familiar thing for the subject in the universe; at the same time, it is the most mysterious thing [1]. Reductionist has insufficient knowledge about its localization and function. It is an open secret issue [2] of humanity and becomes the biggest mystery for both science and philosophy from the last couple of decades. Descartes pointed out that it is the clearest and distinct idea for the subject to be absolutely certain about its existence.

In this paper, we are going to discuss about one aspect of consciousness-phenomenal consciousness. We will be dealing with the question in

\footnotetext{
${ }^{1}$ Chalmers (1995, p.3)

${ }^{2}$ It is the most familiar thing in the universe for the subject because of its peculiar characteristics of indubitableness, subjective certainty and objective truth. At the same time, it's origin (Chalmers called it the hard problem of consciousness- "how consciousness emerges/arises from neurophysiological states of the brain and why it exists at all') has been an open question from the beginning of evolution till now and remains unsolvable mystery. It's the most fundamental problem of human civilisation for us need to be addressed irrespective of different discipline.
}

this paper i.e., what is phenomenal consciousness? Is It real or an illusion? Can reductive physicalism explain it? Is It possible that what we are directly aware of can be a deception? Can phenomenal consciousness be reductively explained? In order to answer these questions, there are two prominent groups (reductionism and non-reductionism) take part in the debate. The debate between reductionist and nonreductionist has been gradually getting more attention within the philosophical community. For eliminative reductionism, there is no such thing as phenomenal consciousness; it is a misleading term frequently used by some philosopher on the influence of primitive ideas of mysticism. Daniel Dennett, one of the leading philosophers of contemporary eliminativists, claims that "phenomenal consciousness are scientifically unsupportable and deeply misleading," [3] there is no phenomenal consciousness exist separately from the brain activities. He has rejected the first-person authority of the agents on their mental facts which is the foundation of non-reductive theories of consciousness.

Phenomenal consciousness is the subjective phenomenal states of the living being, which can be accessible to that specific living being only. It is the 
inner qualitative character of experience neither reducible to mechanical or functional states nor intentional states of experience. Each qualitative, subjective character of experiences are different from each other; for example, every sensory experience (i.e., fragrance of rose, the teste of sweet, etc.) are different from each other and have unique kind of qualitative properties associated with every conscious experience. The qualitative properties of sensory experiences are also different from the non-sensory qualitative properties of experiences. In every mental state or conscious experiences, the qualitative feature of experience [4] always associated, which is inevitable for a conscious being.

If we look at the history of philosophy of mind, then we can find that the debate between the reductionist and non-reductionist camp is primarily based on the view that how consciousness will fit in the physical laws of the universe? Whether mental states can be explained only through the functional states or is there something extra ingredient which cannot be definable through the laws of physics? what is the role of consciousness in the life of an organism? How it emerges from the physical mechanism so and so forth. Reductionist holds that mental states (thoughts, feelings, emotions, happiness, and sensation so and so forth) are somehow identical to brain states or its functional states. For an eliminative reductionist, there is no such thing as phenomenal consciousness, though it seems to exist. Daniel Dennett holds the view that phenomenal consciousness is an illusion. As he pointed out that

"I want to make it as just as uncomfortable for anyone to talk of phenomenal consciousness-or "raw feels" or "phenomenal properties or "qualitative and intrinsic properties" or "the qualitative character" of experience -with the presupposition that they, and everyone else, know what they are talking about...far better, tactically, to declare that there simply are no phenomenal consciousness at all [5]".

There is no such thing exists as phenomenal consciousness, which can be objectively verifiable. The human brain is just a living brain; only activities of the brain exist. He also claims that it is a primitive idea prevailed by some philosopher till now, like a magician tricks the audience through the power of illusion in such a way that the audiences are convinced to accept it as real, like that some philosopher mislead people through some Jugglery words to accept as if there is such a thing called phenomenal consciousness which exist independent of brain functions. He has given some arguments to establish his position, i.e., deflationary theory, illusion arguments.

\footnotetext{
${ }^{4}$ See, Sahu Manas Kumar (2019, pp.78-80)

Qualia and Intentionality for more details.

${ }^{6}$ Block (2008) Vol.108, pp.289-317

${ }^{7}$ Ibid, (1995) Vol.18, No.2, pp.227-247

${ }^{8}$ Chalmers (1995, p.2)
}

On the other hand, there are some contemporary philosophers like David Chalmers, John Searle, Thomas Nagel, Donald D. Hoffman, etc. argues in support of irreducibility of phenomenal consciousness that phenomenal consciousness cannot be explained in terms of the reductionist framework. Generally, there are three popular arguments against reductionist theory of consciousness. These are knowledge argument (K.A), conceivability Argument (C.A), inverted spectrum argument. In every conscious experience, there are some subjective raw feels exist, though there is objectively observable function going on in the brain of the subject at the time of experience. One can measure objectively the functions of the brain that is how the brain works, which part of the brain is responsible for which kind of function and which neuron plays which role in order to generate experience, can answer the question like-what is function of a particular sense organ and what is a particular sensory experience represents, However, what cannot be objectively accessible is the subjective qualitative experience or phenomenal consciousness.

\section{Arguments for Phenomenal consciousness}

There are several arguments which give a rational foundation for believing that phenomenal consciousness is the primordial thing for a living being, which cannot be explained from a third-person perspective. We are going to look at some general argument in this paper. Let us critically analyses some of the popular arguments.

\section{Inverted spectrum argument}

This argument was developed by Ned block and shoemaker against functionalism (in the strong sense) which claims that all mental states are equivalent to functional states. Ned Block has made the distinction between phenomenal consciousness and access consciousness [6], which prevents us from designating him as a strong functionalist [ 7]. As David Chalmers observes "it is possible that a system might make precisely the same color discriminations that I do, but that when confronted by red objects it has the kind of experience that I have when confronted by blue objects. Further, the philosopher argues that this might happen even when the systems are functionally isomorphic. If this argument succeeds, then even if the appropriate functional organization suffices for the existence of conscious experiences, it does not determine their specific nature. Instead, the specific nature of experiences must be dependent on non-organizational properties, such as specific neurophysiological properties [8]." There may be two functionally identical systems but have different qualitative phenomenal consciousness. It is possible that person $\mathrm{X}$ and person $\mathrm{Y}$ having the same verbal report of their experience of the color red, but their subjective inner experience could be 
inverted. When the person $\mathrm{X}$ saw red color has a subjective experience, which is identical to the person Y's experience of yellow and vice versa. Though person $\mathrm{X}$ and $\mathrm{Y}$ have the same color discrimination capacity, it is possible that their inner experience of color inversion might happen in their brain. This color inversion cannot be detected by reductionist (especially behaviorist, neuropsychologist, functionalist and so on) Because they can only explain about the objective function of the brain's color discrimination capacity of the creature but what they are lacking is the knowledge of the direct accessibility of the subjective inner experiences of that creature. There is something like to be that creature [9]. It is possible that the external behavior of two biological systems may be the same, but the qualitative experiences might be different [10]. Even if we completely understand the function of the brain, we cannot be able to give a satisfactory account of phenomenal consciousness in the reductionist approach [11].

\section{Conceivability argument}

Rene Descartes had used this argument to establish his mind-body dualism. Later the argument has redefined to support the non-reductive theory of mind by Saul Kripke and David Chalmers. The underlying essence of the argument is that the possibility of metaphysical gap will be a threat for reductionist thesis. David Chalmers's zombies thought experiment and Saul Kraske's rigid designators are the advanced forms of the conceivability argument.

The argument is grounded on the idea of physical necessity and metaphysical possibility. it defends the view of the irreducibility of phenomenal consciousness by claiming that conceivability entails metaphysical possibility. The argument is, if $\mathrm{X}$ is conceivable then there is no problem for believing its existence in the possible world, because there is no logical contradiction in the idea that $\mathrm{X}$ could exist in the possible world. David Chalmers argues that there can be philosophical zombies, which are behaviorally and functionally identical to human beings, however, lack the phenomenal consciousness. He argues that there is no logical contradiction in the conceivability of philosophical zombies, who act or behave like human being and have the identical function of the human brain but unable to have phenomenal qualitative properties of experience. Though it is not possible in the real world because it is go against the laws of nature or physical necessity of the world, but there is no logical contradiction in the idea of philosophical zombies (like hare's horn, round-square, sky flower and so on). The metaphysical existential possibility of philosophical zombies cannot be ruled out. The logical possibility of zombies entails its existence in the metaphysical world though not in the real world. His main concern was not

\footnotetext{
${ }^{9}$ Nagel (1972), pp.435-450)

${ }^{10}$ Jackson (1986, pp.291-295)

${ }^{11}$ Chalmers (2003, pp.102-142)
}

to argue whether there are zombies exist in the real world or not, but the metaphysical possibilities of their existence. The argument of the Zombies Thought Experiment is

1) If Philosophical zombies are conceivable, then their existence is metaphysically possible. (Conceivability entails metaphysical possibility)

2) If their existence is metaphysically possible, then reductionism is false. (mere possibility of a physical organism devoid of consciousness implies the irreducibility of consciousness.)

3) Philosophical zombies are at least conceivable and existence of zombies is metaphysically possible

4) Therefore, reductionism is false

\section{KNOWLEDGE ARGUMENT}

There is another knockdown argument against reductionist thesis, quite popular among philosopher, known as knowledge argument. There are several forms of knowledge argument developed in the contemporary philosophy of mind. We will limit ourselves within Nagel and Jackson's form of knowledge argument.

\section{What Is It Like To Be a Bat}

The famous article "What is it like to be a bat?" by Thomas Nagel that knowing the physiological structure of an organism is not enough for knowing all the facts about that organism. There are certain facts which cannot be put within the category of physical fact because both of them belong to different categories. The non-physical facts of experience neither can be reduced to nor can be explained objectively due to the limitation of an organism and inaccessibility of the subjective aspect of others mental life. Jackson has explained in his article that "I want to know what it is like for a bat to be a bat. If I try to imagine this, I am restricted to the resources of my mind, and those resources are inadequate to the task. I cannot perform it either by imagining additions to my present experience, or by imagining segments gradually subtracted from it, or by imagining some combination of additions, subtractions, and modifications [12]".

Nagel tries to establish the point here is that everything cannot be explained through the framework of reductionism. Human cognition cannot be grasped the subjective inner experience of an organism. "We may ascribe general types of experience on the basis of the animal's structure and behavior. Thus, we describe bat sonar as a form of three-dimensional forward perception; we believe that bats feel some versions of pain, fear, hunger, and lust and that they have other, more familiar types of perception besides sonar. However, we believe that these experiences also have in each case a specific subjective character, which it is beyond our ability to conceive [13]." The subjective

\footnotetext{
${ }^{12}$ Nagel (1974, p.439)

${ }^{13}$ Ibid. p.439
} 
Manas Kumar Sahu; J Adv Educ Philos, April, 2020; 4(4): 160-166

inner experience of a bat cannot be explained by merely the physiological study of the bat. A neurophysiologist can give all the information about the physiological construction of a bat, how their brain works, which part of the brain of a bat is responsible for the echolocation so and so forth but what any of us could not do is experience the mental life (David Chalmers called it the inner movie of an organism) of a bat. Because all the information is not physical information. There is something beyond the objective explanation of physicalism, which is only accessible to the subject who is having that experience.

\section{What Mary Did Not Know}

Mary is a neurophysiologist who never experienced color, except black and white before, but knows all the physical facts about color that - how the electromagnetic wavelength works, about the functional role of color in the human brain, so and so forth. when she encounters with a red object, will learn something new knowledge about the color red that "what it is like to experience the color red", which she was lacking during her neurophysiological study about the color red. She was not aware about the experience of phenomenal qualities of color red though she knows all the physical facts about the red color before her release. Jackson argues that knowledge of the functional role of the mind is not enough for knowing about the experience of color altogether. "Mary is not that, despite her fantastic grasp of neurophysiology and everything else physical, she could not imagine what it is like to sense red; it is that she would not know. But if physicalism is true, she would know; and no great powers of imagination would be called for [14]." Before her release, Mary knows everything about the color vision and the objective function of the brain but was not aware of the subjective qualitative feature of the color red. "The knowledge Mary lacked which is of particular point for the knowledge argument against Physicalism is knowledge about the experiences of others, not about her own. When she is let out, she has new experiences, color experiences she has never had before [15]".

The argument form of Mary Room Thought Experiment is

1) Mary (before her release) knew all the physical information about color vision (what the best color vision scientist can ever know), but never experience color (Complete Knowledge Claim)

(2) Mary (after her release) learn something new fact about the color vision, which she lacked despite her expertise on neurophysiology. (Learning Claim) Therefore,
(3) There are some facts of color vision which escapes from the Physicalist explanation. (Non-Deducibility Claim) [16]

From the Mary's room thought experiment it is clear that

1) If Mary knows all the physical facts about color vision but lacks phenomenal information, then her knowledge about color vision is incomplete and phenomenal information does not belong to physical information.

2) Mary knew all the physical information (what a best theoretical physicist can ever know), but her knowledge about color vision could not tell her anything about phenomenal information. It is quite contradictory for physicalist (those who accepts all information are physical information) to accept that marry knows all the physical information, but her knowledge is incomplete due to lack of phenomenal information. Because to argue that $\mathrm{X}$ has complete knowledge about $\mathrm{Y}$, however, unable to identify a property of $\mathrm{Y}$ is a contradictory idea. If $\mathrm{X}$ knows all the information about Y completely, then he/she will not miss any information about $\mathrm{Y}$. it challenges the fundamental concept of physicalist that all information is physical information.

3) Therefore, there is something about the color vision which is not contained by Mary's physicalist theory of knowledge of color experience and the physicalist assumption that all information are physical information become false. What Mary was lacking in spite of knowing all the physical facts about color was the phenomenal information ("what is it like to experience color," subjective qualitative raw feels about color, what is it like to experience redness of red, greenness of green, etc.).

\section{Reductionist Responses to Knowledge Argument}

The knowledge argument has become controversial from a long time ago. Physicalist deferred in their standpoint in response to the argument. Generally, physicalist can be categorized broadly into two groups, namely thick and thin materialism [17]. If Mary knows all the physical facts of color vision, then she will definitely make the right predictions about the sensory data about color and will not surprise in her after released experiences [18]. Dennett argues that if premise one is true then premise two must be false because knowing all the physical facts about color vision means knowing everything about color vision. By knowing the physical effects and causes of color vision Mary definitely will be able to figure out what

\footnotetext{
${ }^{16}$ Hence all information is physical information became false.

${ }^{17}$ See Chalmers (2002, pp.247-55) for detailed analysis.

${ }^{18}$ See Dennett (2017, pp.1-8), and (2006, pp.15-31)
}

\footnotetext{
${ }^{14}$ Jackson (1986, p.292)

${ }^{15}$ Ibid. p.292
} 
supporter of knowledge argument called what it is like to experience color [19].

A question may arise here that in order to have phenomenal experience of color, do we really need the direct access of color or can the phenomenal experience of color is possible without the experience of color red? In fact, those who endorse simulation theory can claim that the same phenomenal experience of color can be generated through simulation without direct access to the content of experience i.e. color red. If there is no need for content of experience to generate phenomenal experience, then Mary knows what it is like to experience red before her release [20].

The possibility of environmental stimuli replacement cannot be denied, however, generating experience through direct access to the perceptual content and generating the experience by the help of stimulation will be different all together. In both cases, the role of neurophysiological substances may be identical, however, will generate different experience altogether. In the first case the subject will have the self-awareness about the perceptual content entangled with the phenomenal subjective experience whereas in the latter case, no such thing is possible.

\section{Non-propositional Knowledge}

Unlike Dennett, the second category of physicalism accept that Mary learns something about color vision after her release, however the knowledge she got was not propositional knowledge (certain information of experience) about the color experience but a non- propositional knowledge [21]. The proponents of this argument claim that propositional knowledge (knowing that) is not the same as nonpropositional knowledge (knowing how). What Mary learn was non- propositional knowledge about color vision. Mary, before her release, aware about the possibility of

\footnotetext{
${ }^{19}$ Dennett's (2006, pp.14-29) objection to knowledge argument can be a threat for weaker (earlier) version of the knowledge argument only, however, K.A can be protected from Dennett's attack by modifying the argument. The phenomenal realist can counter the Dennett's response by revising the knowledge argument that Mary before her release, knows all most all the physical information what a neurophysiologist can know through theoretical studies of color vision.

${ }^{20}$ Torin (2008, pp. 247-50)

21 There is a common agreement between ability hypothesis and acquaintance hypothesis on the nonpropositional knowledge. D. Lewis (1983 Vol.12, pp.112-133), (1988 vol.13, pp.29-57) and Nemirow (1980), (1990), (2007) criticized the knowledge argument by advocating the ability hypothesis. Conee's (1994) attack is based on acquaintance hypothesis. Tye (2000), (2009 p.113) reformulate the acquaintance hypothesis, Mellor (1993), and Meyer (2001) argues in support of ability hypothesis.
}

phenomenal subjective knowledge of experience indirectly. She lacked only certain abilities/ acquaintance property of experience because of which she could not gain phenomenal information directly. (ability hypothesis). There are two kinds of nonpropositional claim a) acquaintance hypothesis b) ability hypothesis,

The proponent of acquaintance hypothesis argues that the phenomenal subjective experience of color is directly supereminence on the acquaintance of color experience. Mary before her release, was never acquainted with color red that's why she lacks the acquaintance property of color experience.

Ability hypothesis accepts the premises of knowledge argument; however, it rejects the conclusion that Mary will gain a new knowledge about color vision. Though it partially agrees with K.A that she lacked certain information before experiencing color red, but that is not phenomenal or factual knowledge (propositional knowledge) rather she acquires certain abilities which are come under category of nonpropositional knowledge. When Mary sees the red color for the first time, she will gain certain abilities (i.e., remembering, recognizing, and making predictions) instead of new knowledge or concepts [22]. Phenomenal knowledge without ability is possible, however, ability without phenomenal knowledge is not possible. Mary not only gain certain new ability but also learns new fact about Color. (a phenomenal realist can accept the ability hypothesis claim that she gains certain new ability without accepting the claim that abilities are identical with the phenomenal knowledge). The knowledge argument can also be defended against ability hypothesis by claiming that Mary not only gain certain imaginative ability rather something new along with the complex ability [23].

\section{Common Agreement of K.A and C.A}

knowledge argument and the conceivability argument rely on three common ideas despite of different stands on intersubjectivity.

Explanatory Gap: - There is an explanatory gap between phenomenal consciousness or phenomenal consciousness and physical structure of the brain, which is a big challenge for any reductionist theory of mind. They have a mutual agreement on the view that there is an explanatory gap between physical information and phenomenal information; physical information is insufficient for explanation of phenomenal subjective experience. Hence there is something beyond the realm of physical information. (physical information phenomenal information). No amount of physical fact/knowledge of experience can explain "what is it

\footnotetext{
${ }^{22}$ For Comprehensive Analysis See Nemirow (2007 pp.490-499) "So This is What it's Like: A Defense of The Ability Hypothesis"

${ }^{23}$ See Torin Alter (2008, pp.229-39)
} 
like to be in certain mental states" because of the inaccessibility of mental content by others. Phenomenal concept/knowledge is a priori irreducible form physical facts/concepts/knowledge of experience.

\section{Ontological Gap}

One can easily infer the ontological gap from the possibility of epistemic gap. In Jackson's knowledge argument, Mary knows (after her release) that there is something about the color experience which she lacked (before her release) in spite of knowing all the physical facts/knowledge about the color vision. It leads to her to infer that there are certain non-physical facts about color experience, which is out of the realm of physicalist explanation. The epistemic gap implies the possibility of a metaphysical gap. Therefore, there is no inconsistency in the idea that there is a metaphysical gap which physicalists were failed to deal with. The conceivability argument (C.A) has a quite similar view that the metaphysical possibility of zombies is irrefutable.

\section{Inconsistency with Reductive Physicalism}

Both of the arguments share the common idea that physicalism is inconsistent with phenomenal information. Physicalist either try to deny the possibility of phenomenal information or reduced to physical information which is not acceptable to both

C.A and K.A. The physicalist also accepts that the mere possibility of the metaphysical gap implies the falsity of physicalism. The debate on the phenomenal and subjective aspect of the experience with physicalist has become a classic and overwhelming issue.

\section{Phenomenal Concept Strategy}

Phenomenal concepts are constructed by the conscious agent through the introspection of phenomenal experience. Hence, they are experience dependent. In order to explain the phenomenal experience, we use certain concepts which are distinct from other physical concepts named as Phenomenal Concept. The construction of a particular phenomenal concept by the subject is possible when the subject undergone a certain type of experience from which the acquisition of particular phenomenal concept about the content of experience became possible. The phenomenal concept strategy supporters [24], unlike type A materialist (eliminativists), acknowledge that there is an explanatory gap [25] between phenomenality of experience and physical basis of experience (accept knowledge claim and learning claim of knowledge argument), however, they oppose the conclusion of

\footnotetext{
${ }^{24}$ Lora (1997), Stoljar (2005), Papineau (2006), and Carruthers \& Veillet (2007) are the proponents of Phenomenal Concept Strategy.

25 The proponent of phenomenal concept strategy (P.C.S) used the term Explanatory Gap in a special sense which is completely different from Usage of nonphysicalist explanation of Explanatory Gap.
}

knowledge argument. The anti-materialist explanation of phenomenal concepts as nonphysical property is misleading. The phenomenal concepts can be explained through the computational mechanism of the brain that how the particular events of the neural processes are responsible for generating these phenomenal concepts [26].

Phenomenal concepts are purely recognitional [27] generated only through the acquaintance with the object of experience. The knowledge of phenomenal experience of color red for instances is only possible, when there is the possibility of deploying that specific phenomenal concept of red, which is constructed through prior experience. As we have seen in the conceivability argument that Mary lacked the phenomenal experience of red before her release not because she lacked the non-physical and irreducible fact about color in the anti-physicalist term, because she was conceptually isolated from the phenomenal concept about the experience of color red. Each phenomenal concept is tied with a particular type of experience, the change in phenomenal experience cause the change in phenomenal concepts. The inseparability of phenomenal concepts from experience establish the fact the anti-physicalist arguments are misleading.

The response of phenomenal concept strategy to anti-physicalist arguments is implausible, as David Chalmers argues that in order to bridge the explanatory gap, it invites another explanatory gap between neurophysiological processes and phenomenal concepts.

\section{CONCLUSION}

The debate between reductionist and nonreductionist camp on phenomenal consciousness grounded on the primary assumptions that everything in the universe can be explained either in terms of physicalist mechanism or non-physical explanation of reality. These are the two approach which prevails from the beginning of philosophy. The anti-physicalist arguments have the problem of establishing their knowledge claim without giving the physical basis for evaluation to physicalist, which might be a possible way to resolve the issue. On the other hand, physicalist mechanism has this biasness that everything can be reduced to matter or representational properties of experience. The job of a naturalist is just to give a mechanistic explanation of the world through reduction to matter. The common agreement between antiphysicalist arguments on the explanatory gap is an initial challenge for any reductionist thesis in the first place which must be addressed before having a theory of consciousness. it is an uncontroversial claim that phenomenal consciousness secures the ground for subjective certainty of knowledge, however, as Ned

\footnotetext{
${ }^{26}$ See Papineau (2006, pp.111-44)

${ }^{27}$ See Carruthers \& Veillet (2007, pp. 215-17)
} 
Manas Kumar Sahu; J Adv Educ Philos, April, 2020; 4(4): 160-166

Block pointed out, there is a potential threat in this approach which may lead towards solipsistic world view. In other words, though it secured the ground for subjective certainty, might be failed to address the harder problem, as we have seen in the case of foundationalism.

\section{REFERENCES}

1. Alter, T., \& Walter S. (eds.). (2006). Phenomenal Concepts and Phenomenal Knowledge: New Essays on Consciousness and Physicalism. Oxford University Press

2. Alter, T., (2008). Phenomenal Knowledge Without Experience. In Edmond Wright (ed.), The case for phenomenal consciousness. MIT Press 247-67

3. Alter, T., (2008). Know- How, Ability, and the Ability Hypothesis. Theoria, 67, 229-239

4. Block, N., (2008). Phenomenal and Access Consciousness Ned Block and Cynthia MacDonald: Consciousness and Cognitive Access. Proceedings of the Aristotelian Society.108, 289317

5. Block, N., (1995). On a Confusion About a Function of Consciousness. Behavioral and Brain Sciences. 18:2, 227-47

6. Carruthers P., \& Veillet B., (2007). The Phenomenal Concept Strategy, Journal of Consciousness Studies, 14:10-09, 212-36

7. Chalmers J. D., (1995). Absent Qualia, Fading Qualia, Dancing Qualia, Conscious Experience Imprint Academic, 309-28

8. Chalmers J. D., (1996). The Conscious Mind-In Search of a Fundamental Theory, Oxford University Press

9. Chalmers J. D., (2002). Philosophy of Mind: Classical and Contemporary Readings, Oxford University Press, 247-73

10. Chalmers J. D., (2003). Consciousness and Its Place in Nature, Blackwell Guide to the Philosophy of Mind. Blackwell, 102-42

11. Conee, E., (1994). Phenomenal knowledge, Australasian Journal of Philosophy, 72:2, 136-50

12. Dennett, D. C., (1988). Consciousness in Modern Science, Oxford University Press. (Reprinted in W. Lycan, ed., Mind and Cognition: A Reader, MIT Press, 1990) (A. Goldman, ed. Readings in Philosophy and Cognitive Science, MIT Press, 1993)

13. Dennett, D. C., (2006). What Robo Mary knows. In Torin Alter \& Sven Walter (eds.), Phenomenal Concepts and Phenomenal Knowledge: New Essays on Consciousness and Physicalism. Oxford University Press, 15-31

14. Dennett, D. C., (2017). A History of Qualia. Topoi, $1-8$
15. Gertler, B. (1999). A Defense of the Knowledge Argument. Philosophical Studies: An International Journal for Philosophy in the Analytic Tradition, 93:3, 317-336

16. Sarihan, I. (2017). The Internalist-Intentionalist Research Program: Towards a New Paradigm for an Analysis of Consciousness and Mental Content, (Ph.D. Thesis)

17. Jackson, F. (1986). What Mary did not Know, The Journal of Philosophy, 83:5,291-95

18. Jackson, F. (1982). Epiphenomenal Qualia. The Philosophical Quarterly, 32:127, 127-36

19. Lewis, D. (1983). Postscript to "Mad Pain and Martian Pain," in D. Lewis, Philosophical Papers, Oxford: Oxford University Press.12, 112-33

20. Lewis, D. (1988). What Experience Teaches, Proceedings of the Russellian Society, 13, 29- 57

21. Loar, B. (1990). Phenomenal States, Philosophical Perspectives, 4, 81-108

22. Mellor, D. H. (1993). Nothing Like Experience. Proceedings of the Aristotelian Society, 93, pp.1-16

23. Meyer, U. (2001). The Knowledge Argument, Abilities, and Metalinguistic Beliefs, Erkenntnis, 55, 325-47.,

24. Nagel, T. (1974). What is It like To Be a Bat, Philosophical Review, Duke University Press, 43550

25. Nemirow, L., (1980). Review of Thomas Nagel, Mortal Questions, Philosophical Review 89, 47377.

26. Nemirow, L. (1990). Physicalism and the Cognitive Role of Acquaintance. In W. Lycan (Ed.), Mind and cognition Oxford: Blackwell, 490- 99,

27. Nemirow, L. (2007). So This is What It's Like: A Defense of the Ability Hypothesis, in T. Alter \& S. Walter, Phenomenal Concepts and Phenomenal Knowledge: New Essays on Consciousness and Physicalism, 32-51.

28. Papineau, D. (2006). Phenomenal and Perceptual Concepts, In Alter, Torin \& Walter Sven (eds.) Phenomenal Concepts and Phenomenal Knowledge: New Essays on Consciousness and Physicalism. Oxford University Press, 111-44

29. Sahu, M. K. (2019). Qualia and Intentionality, Journal of All Odisha Philosophy Association, 5:1, 76-87

30. Stoljar, D. (2005). Physicalism and Phenomenal Concept, Mind and Language, 20, 469-94

31. Tye, M. (2000). Knowing What It is Like: The Ability Hypothesis and The Knowledge Argument. Protosociology, Collection of Essays for David Lewis.

32. Tye, M. (2009). Consciousness Revisited: Materialism Without Phenomenal Concepts, MIT Press, Cambridge, 95-116. 